BIBLID: 0015-1807, 47 (2020), 2 (pp. 63-75)

UDK 811.134.1:930.85(467.1)(091)

https://doi.org/10.18485/fpregled.2020.47.2.4

\author{
Pau Bori \\ Univerzitet u Beogradu - Filološki fakultet \\ pau.bori.sanz@fil.bg.ac.rs \\ Ana Kuzmanović Jovanović \\ Univerzitet u Beogradu - Filološki fakultet \\ akuzmanovic@fil.bg.ac.rs
}

\title{
KATALONSKI JEZIK: ISTORIJSKI, POLITIČKI I DRUŠTVENI KONTEKST
}

\begin{abstract}
Apstrakt: Cilj ovog rada je da predstavi istorijski, politički i društveni kontekst razvoja katalonskog jezika, kao i sociolingvističku situaciju u tzv. katalonskim zemljama. Ovaj razvoj predstavljen je iz hronološke perspektive, od ranog srednjeg veka, preko perioda teritorijalne ekspanzije Katalonije i Zlatnog doba katalonske kulture i književnosti (XV vek), sve do gubitka političke i jezičke autonomije (XVIII vek), te jezičke i kulturne obnove (druga polovina XIX vek) i standardizacije jezika (u prvoj polovini XX veka), sve do progona katalonskog u vreme frankizma (druga polovina XX veka). $\mathrm{Na}$ kraju, predstavljena je savremena sociolingvistička situacija na teritorijama gde se govori katalonski jezik, u kontekstu novih demografskih, političkih i socio-ekonomskih tendencija.
\end{abstract}

Ključne reči: katalonski jezik, sociolingvistička istorija, Katalonija, bilingvizam.

\begin{abstract}
The purpose of this article is to present the development of the historical, political and social context of the Catalan language, as well as the current sociolinguistic situation in the Catalan-speaking territories. This development is exposed in a chronological way, beginning with the origins of Catalan at the end of the High Middle Ages, continuing through its territorial expansion and what is considered the golden age of its literature (the $15^{\text {th }}$ century). Next, we explain the loss of political and cultural power aggravated in the $18^{\text {th }}$ century, the revitalization of the language in the second half of the $19^{\text {th }}$ century and its normalization in the first decades of the $20^{\text {th }}$ century, as well as its persecution during the Franco dictatorship. Finally, we present the contemporary sociolinguistic situation in the territories where Catalan is spoken, within the framework of the new demographic, political and socioeconomic trends.
\end{abstract}

Keywords: Catalan language, sociolinguistic history, Catalonia, bilinguism.

\section{Uvod}

Katalonski je romanski jezik sa devet miliona govornika u četiri države. Najveći broj govornika je u Španiji, gde se govori u nekoliko autonomnih pokrajna: Kataloniji, Balearskim ostrvima, Valensiji i u pograničnoj zoni sa Aragonom. 
Katalonski je, zatim, i zvaničan jezik pirinejske države Andore, a govori se i na jugu Francuske, u departmanu Istočni Pirineji (fr. Pyrénées-Orientales), kao i u gradu Algero (Alghero) na Sardiniji.

Prema broju govornika, katalonski se može uporediti sa drugim evropskim jezicima, poput holandskog, srpskog ili finskog. Međutim, poseduje određene specifičnosti koje ga od tih jezika odvajaju. Pre svega, katalonski nije zvaničan jezik nijedne države (ako izuzmemo minijaturnu kneževinu Andoru). Osim toga, na svim teritorijama na kojima se govori prisutan je bilingvizam u određenom stepenu, pre svega katalonsko-španski, ali i katalonsko-francuski ili katalonsko-italijanski. ${ }^{1}$

\section{Istorijske okolnosti razvoja katalonskog jezika}

Da bi se bolje razumela sociolingvistička situacija savremenog katalonskog jezika, predstavićemo ukratko njenu istoriju, uz osvrt na političke i društvene okolnosti koje su je oblikovale.

\subsection{Poreklo}

Veoma je teško precizno odrediti trenutak kada se katalonski (ili bilo koji drugi romanski jezik) u potpunosti odvojio od latinskog. Naime, u čitavoj evoluciji romanskih jezika iz latinskog postojao je vertikalni kontinuum registara, od strogo kodifikovanog književnog, tj. klasičnog latinskog, do različitih geografskih varijeteta govornog latinskog jezika. ${ }^{2}$ Uz postepeno sve jače opadanje antičke kulture, opadao je i stepen razumevanja između različitih registara unutar kontinuuma latinskog jezika. ${ }^{3}$ No tek sa karolinškim reformama pisanog latinskog jezika (IX vek) i njegovog ponovnog približavanja antičkom standardu, po prvi put se među romanizovanim stanovništvom zapadne Evrope javila jezička svest o tome da jezik koji govore nije više latinski.

Istoričari katalonskog jezika slažu se da je do ovog prekida kontinuuma i konstituisanja katalonskog kao nezavisnog jezika došlo postepeno, u periodu između VII i IX veka ${ }^{4}$ Katalonski je nastao na teritoriji Karolinškog carstva, u oblasti Pirineja (današnji sever Katalonije, Andora i jug Francuske) poznatoj kao Španska marka (Marca Hispànica). U pitanju su grofovije koje je ustanovio

${ }^{1}$ Emili Boix-Fuster \& Jaume Farràs, "Is Catalan a medium-sized language community too" in Survival and development of language communities prospects and challenges, ed. F. X. Vila, Bristol, Multilingual Matters, 2012, str. 157-178.

${ }^{2}$ Michel Banniard, "The Transition from Latin to Romance Languages" in The Cambridge History of Romance Languages, ed. M. Maiden et al., Cambridge, Cambridge University Press, 2013, str. 57-106.

${ }^{3}$ Vid. Roger Wright, "Periodization" in The Cambridge History of Romance Languages, ed. M. Maiden et al., Cambridge, Cambridge University Press, 2013.

${ }^{4}$ Antoni Ferrando \& Miquel Nicolás, Història de la llengua catalana. Barcelona, Editorial UOC, 2011. 
Karlo Veliki u VIII veku, kao neku vrstu odbrambene zone prema Al-Andalusu, teritoriji Iberijskog poluostrva koju su početkom tog istog veka osvojili Mavari, islamski osvajači sa severa Afrike.

Dokaz da se u pomenutoj oblasti u IX veku više nije govorio latinski jeste zvanična preporuka Sabora (koncila) u Turu (fr. Tours) sveštenstvu iz 813. godine da propovedaju na 'rustičnom', to jest narodnom, a ne latinskom jeziku, kako bi narod mogao da ih razume. ${ }^{5} \mathrm{U}$ tom najranijem periodu, rustični (narodni) katalonski jezik bio je korišćen isključivo u usmenim domenima upotrebe, dok je latinski još dugi niz vekova, kroz čitav rani Srednji vek, ostao jedini pisani jezik.

Prvi tragovi pisanog katalonskog jezika predstavljaju glose - pojedinačne reči ili fraze umetnute u latinske tekstove iz IX veka. Pisari koji su sastavljali kupoprodajne ugovore, testamente ili bilo koju drugu vrstu dokumenata na latinskom, povremeno bi ubacivali u tekst reči i izraze iz govornog jezika. Ovaj fenomen glosiranja nalazimo od VII veka u svim delovima Romanije (teritorije na kojoj se od Antike govorio latinski jezik) i posledica je slabljenja kontinuuma između formalnih (pisanih) i neformalnih (usmenih) registara latinskog jezika. ${ }^{6}$

Ipak, potreba da se narod upozna sa važećim zakonskim, crkvenim i društvenim normama uticala je na to da romanski jezici postepeno počnu da osvajaju i formalne, pisane domene upotrebe. Kada je u pitanju katalonski, prvi tekstovi integralno napisani na katalonskom pripadaju upravo religioznom i pravnom žanru. To su:

a) prevod na katalonski starog srednjovekovnog vizigotskog zakonika Liber Iudicorum (XII vek);

b) Les Homilies d'Organyà (početak XIII veka), zbirka propovedi nepoznatog sveštenika iz manastira Organja koji prevodi i komentariše Jevanđelja i Poslanice napisane originalno na latinskom jeziku.

U oba teksta očigledan je uticaj provansalskog (oksitanskog) jezika sa juga današnje Francuske. Ovaj uticaj može se pripisati genealoškoj srodnosti dva jezika, kao i bliskim istorijskim i kulturnim vezama Provanse i Katalonije, koje su u jednom trenutku srednjeg veka (između XII i XIII veka) formirale i jedinstven politički entitet.

\subsection{Ekspanzija}

Aragonska kruna ${ }^{7}$ izgubila je od francuskih trupa 1213. godine čuvenu bitku kod Murea (Muret) na jugu Francuske, čime su odloženi njeni planovi za dalje širenje prema severu. Tada se ekspanzionistička politika katalonskih kra-

${ }^{5}$ Ova preporuka odnosila se na sve teritorije Karolinškog carstva, u kojima su se tokom ranog srednjeg veka razvili različiti romanski i germanski varijeteti, videti Banniard, op. cit., str. 76.

${ }^{6}$ Roger Wright, nav. delo, str. 131.

${ }^{7}$ Katalonsko-aragonska konfederacija poznata je u srpskoj istoriografiji kao Aragonska kruna ili Kruna Aragona. Nastala je ujedinjenjem grofovije Barselone i kraljevine Aragon u XII veku i potrajala sve do XVIII veka i rata za špansko nasleđe, nakon kojeg je izgubila svaku autonomiju. 
ljeva okreće prema jugu. U periodu od XII do kraja XIII veka katalonski vladari osvojili su od Mavara važne teritorije: Leridu (Ljeidu), (1149), Balearska ostrva (1229-1287) i Valensiju (1233-1264). Posledice ovih osvajanja od ogromnog su značaja za istoriju katalonskog jezika. Naime, zahvaljujući njima:

a) značajno je proširena teritorija katalonskog jezika;

b) razvila su se dva velika dijalekatska bloka katalonskog jezika, koja su opstala do danas: zapadni blok (Lerida/ Ljeida i Valensija) i istočni blok (Barselona i Balearska ostrva);

c) pored Barselone, nastala su još dva važna centra kodifikacije i širenja jezičkih modela: Valensija i Majorka.

U narednom periodu, između XIII i XVI veka, kada je aragonska kruna proširila svoje teritorije i uticaj po Sredozemlju - Siciliji, Sardiniji, Napulju, sve do Atine - katalonski jezik je već bio dovoljno elaboriran u svim domenima upotrebe, uključujući i one formalne: administraciju, pravo ali i književnost.

Kraljevska kancelarija (La Cancelleria Real) bila je administrativni organ Aragonske krune. Dokumenta koja je izdavala bila su model katalonskog jezika u ondašnjem društvu, čime je Kraljevska kancelarija preuzela na sebe jezičku kodifikaciju i standardizaciju.

\subsubsection{Pravni tekstovi}

Među različitim pravnim tekstovima na katalonskom iz pomenutog perioda, posebno se ističe Konzularna pomorska knjiga (El Llibre del Consolat de Mar, 1320-1330), zbornik zakona o pomorskoj trgovini koji su važili u čitavom Sredozemlju sve do XVIII veka.

\subsection{2. Četiri velike hronike}

Pod ovim nazivom poznata su četiri dela napisana na katalonskom jeziku krajem XIII i tokom XIV veka, sa ciljem da se zabeleže određeni istorijski događaji, ali koja pored istorijskog poseduju i didaktički karakter. U pitanju je jedno od najboljih istoriografskih dela srednjovekovne Evrope. U njemu se pripovedaju podvizi različitih kraljeva katalonsko-aragonske krune. Autori ovih hronika direktni su očevici događaja o kojima pripovedaju, a njihov stil odlikuje uzvišeni i patriotski ton.

\subsection{Ramon Ljulj (Ramon Llull)}

Od druge polovine XIII veka, kao posledica krize feudalnog sistema i razvoja trgovine, javlja se nova društvena klasa, buržoazija, čija će uloga u katalonskom društvu postepeno sve više jačati. Pojava ove nove klase dovešće do presudnih kulturnih promena, među kojima se posebno ističe upotreba katalonskog (naporedo sa latinskim) kao jezika kulture, kao i stvaranje prozne književnosti namenjene široj narodnoj publici. 
U ovaj kontekst treba smestiti i Ramona Ljulja (1232-1316), Majorčanina i potomka barselonske porodice koja je učestvovala u osvajanju Majorke, čije delo predstvlja začetak katalonske književnosti. Značaj Ljuljovog dela leži najpre u njegovoj raznovrsnosti, budući da je pisao ne samo poeziju i proznu fikciju, već i naučnu i filozofsku prozu. Svojim elegantnim i preciznim stilom Ljulj je transformisao novonastali jezički model Kraljevske kancelarije, u potpunosti ga osposobivši za filozofsko i književno stvaralaštvo.

\subsection{Narodno stvaralaštvo}

Iako nema sačuvanih pisanih svedočanstava, izvesno je da je u pomenutom periodu cvetala i narodna književnost (ljubavna poezija, epika i drugo). Neki fragmenti ovog narodnog stvaralaštva sačuvali su se zahvaljujući tome što su zapisani u pomenute četiri hronike.

\subsection{Uspon Valensije}

Posle smrti katalonskog kralja Martija Humanog (Martí l'Humà), koji nije ostavio potomke, 1410. godine nestaje katalonska kraljevska dinastija i na presto aragonskog kraljevstva dolazi kastiljanska dinastija Trastamara (Los Trastámara). Ovaj događaj, praćen brojnim društvenim i klasnim previranjima, kao i opadanjem značaja Barselone kao centra trgovine u Sredozemlju, doveo je do duboke krize u Kataloniji i uspona Valensije kao novog ekonomskog i kulturnog epicentra Aragonske krune.

Tako su u XV veku, u tzv. Zlatnom veku katalonske književnosti, najvažniji pisci ovog jezika poticali upravo iz Valensije. Među njima se posebno ističu romanopisac Đuanot Martorelj (Joanot Martorell) i pesnik Auzijas Mark (Ausiàs March).

Đuanot Martorelj je autor čuvenog viteškog romana Tirant Beli (Tirant lo Blanch, 1490), u kojem opisuje avanture viteza Tiranta Belog po Mediteranu stilom koji kombinuje uzvišen ton, retoriku i viteštvo sa humorističkim opisima, kolokvijalnim izrazima pa čak i pikanterijama koje su sigurno oduševljavale ondašnju publiku, a dopadaju se i onoj savremenoj. Za razliku od tradicionalnih viteških romana, u Tirantu Belom nema čudesnih mesta ni nadljudskih sila koji određuju sudbinu junaka. Tirantova sudbina zavisi isključivo od njega samog. U Don Kihotu, Migel de Servantes kroz jednog od svojih junaka kaže kako Tiranta Belog treba spasiti lomače, budući da se radi o najboljoj knjizi na svetu.

\subsection{Auzijas Mark (Ausiàs March)}

Valensijanac Auzijas Mark smatra se prvim velikim pesnikom katalonskog jezika. Svakako, treba istaći da je na teritoriji Aragonske krune poezija na narodnom jeziku cvetala još u XII i XIII veku. Bila je to trubadurska poezija, ali negovana ne na katalonskom, već na oksitanskom jeziku. Trubadurska poezija, 
koja odražava vrednosti i protivurečnosti feudalnog društva i iz koje potiče i moderna evropska poezija, imala je ogromnog uticaja u čitavom basenu Sredozemlja.

Treba istaći da upotreba dva jezika u okviru jedne kulture, jednog za prozno (katalonski) a drugog za poetsko stvaralaštvo (oksitanski) nije fenomen vezan isključivo za srednjovekovnu Kataloniju. Istu diferencijaciju nalazimo u tom periodu, na primer, i u kraljevini Kastilji, na dvoru kralja Alfonsa X Mudrog, gde je kastiljanski bio jezik proze, a galisijsko-portugalski jezik poezije.

\subsection{Prevodi}

Tokom srednjeg veka, Katalonija je održavala bliske kulturne veze sa Italijom. Jedan od prvih prevoda Danteove Božanstvene komedije bio je upravo prevod na katalonski jezik Andreu Febrera. Osim toga, na katalonski su prevođena i druga velika dela evropske antičke i srednjovekovne književnosti, poput Bokačovog Dekamerona ili Ovidijevih Heroida.

\subsection{Govorni katalonski jezik u XIV i XV veku}

Svedočanstva govornog katalonskog jezika iz XIV i XV veka sačuvana su zahvaljujući dokumentima iz sudskih procesa, u kojima je živ jezik verno transkribovan.

Za govorni jezik iz ovog perioda veoma su važne i propovedi valensijanskog dominikanskog monaha Visenta Ferera (Vicent Ferrer, 1350-1419), sačuvane zahvaljujući beleškama kako samog Ferera, tako i njegovih sledbenika i učenika. ${ }^{8}$ Njegove propovedi imale su za cilj da približe hrišćanski moral širokoj, neobrazovanoj i nepismenoj publici, zbog čega je koristio kolokvijalan jezik pun uzvika, narodnih izraza, parabola i slično. U pitanju je bio sasvim drugačiji jezički model od onog koji je elaborirala Kraljevska kancelarija, administrativni organ katalonsko-aragonske krune. Ferer je prošao pola Evrope propovedajući, neprestano se koristeći svojim maternjim jezikom, katalonskim iz Valensije, no publika ga je uvek razumela. Ova činjenica govori u prilog tezi da u ono vreme romanski jezici još uvek nisu bili u potpunosti izdiferencirani, naročito kada su u pitanju određeni stilovi i žanrovi, poput religioznih propovedi.

\subsection{Rođenje i uspon katalonskog jezika: zaključak}

Katalonski se, poput drugih romanskih jezika, postepeno razvija iz latinskog jezika u ranom Srednjem veku, između VII i IX stoleća, a sve domene upotrebe osvaja u XV veku u Valensiji. Najpre su se pojavili katalonski izrazi i reči umetnute u latinske tekstove, tzv. glose, no kasnije je katalonski postao jezik kulture za sve vrste žanrova (prozu, poeziju, filozofiju i dr.) i nacionalni jezik jedne jasno izdiferencirane jezičke zajednice, kao i zvaničan jezik jedne države, Aragonske krune.

${ }^{8}$ Francisco Gimeno Blay, "Modelos de transmisión textual de los sermones de San Vicente Ferrer: la tradición manuscrita", Anuario de Estudios Medievales, 49(1), 2019, str. 137-169. 
U ovom procesu važnu ulogu imale su, s jedne strane, neprekinute aktivnosti jedne institucije, Kraljevske kancelarije, kao i talenat i trud velikih pisaca koji su krunisali svoj maternji jezik, poput Ramona Ljulja, Auzijasa Marka ili Đuanota Martorelja. Kombinacija ovih faktora dovela je do formiranja srednjovekovnog katalonskog koinea, tj. zajedničkog modela jezika.

\section{Period jezičke dekadencije}

Moderna epoha donela je zemljama katalonskog jezika gubitak političkog suvereniteta koji su obeležila tri istorijska događaja:

1) dinastičko ujedinjenje sa Kastiljom u XV veku,

2) centralizam Habsburgovaca koji su vladali Španijom u XVI i XVII veku,

3) poraz od trupa Burbonske dinastije u XVIII veku.

Prestiž i dominacija kastiljanskog jezika uticali su na to da mnogi katalonski pisci prestanu da koriste katalonski u njegovu korist. Ipak, narodni, usmeni jezik na teritorijama Aragonske krune sve do XIX veka nastavio je da bude katalonski. Osim među aristokratijom, vladajućom klasom i obrazovanim slojevima stanovništva (koji su činili ogromnu manjinu), kastiljanski se nije koristio i nije bio poznat širokim narodnim masama.

Poraz Katalonije u Ratu za špansko nasleđe (Guerra de Sucesión de la corona de España, 1704-1714) imao je ozbiljne posledice po katalonski jezik. Oblasti koje su činile Aragonsku krunu bile su u ovom ratu na strani nadvojvode Karlosa i borile se, zajedno sa saveznicima, protiv Kastilje i burbonskih trupa. Posle pada Barselone (1714), Katalonija je izgubila ne samo rat, već i sve institucije vlasti, a katalonski je prestao da bude zvaničan jezik države i obrazovanja. Osim toga, zabranjene su bile čak i knjige, štampa i pozorišne predstave na ovom jeziku.

U praksi, međutim, ove zabrane nisu imale efekta sve do XIX veka i uspostavljanja nacionalnih država. Uprkos represijama i pritiscima, međutim, katalonski narod je sačuvao živim svoj jezik. Tek u XX veku, nakon velikih ekonomskih, političkih i demografskih promena, pojavila se prva generacija bilingvalnih (katalonsko-kastiljanskih) Katalonaca.

\section{Revitalizacija katalonskog jezika}

U romantizmu, paralelno sa jačanjem nacionalističkih ideologija i pokreta širom Evrope, i katalonski jezik ulazi u fazu obnove u drugoj polovini XIX veka.

Tada katalonski ponovo postaje jezik književnosti; na njemu se pišu dela univerzalne vrednosti i ogromne popularnosti, a među autorima se posebno ističu pesnik Đasint Verdager (Jacint Verdaguer), romanopisac Narsis Oljer (Narcís Oller) i dramaturg Anđel Gimera (Àngel Guimerà). Istovremeno, započinje sistematsko proučavanje katalonskog jezika, izrada rečnika, lingvističkih traktata i pravopisa, kako u Kataloniji, tako i u Valensiji i na Balearskim ostrvima. Osim 
toga, katalonski postaje i jezik lokalne i nacionalne štampe i izdavaštva na čitavoj teritoriji Španije gde se katalonski govorio.

Sve ove aktivnosti predstavljaju neposrednu pripremu za modernu normativizaciju jezika započetu početkom XX veka.

\section{Normativizacija}

Početkom XX veka, nacionalističke politike u Kataloniji obnovile su upotrebu katalonskog jezika u obrazovnom sistemu i u državnoj administraciji.

Posebnu podršku institucionalnoj upotrebi katalonskog jezika dao je Enrik Prat de la Riba (Enric Prat de la Riba), političar, mislilac i pisac, jedan od vodećih predstavnika katalonskog nacionalizma s početka XX veka. On je 1907. godine osnovao Institut za katalonske studije (Institut d'Estudis Catalans), u okviru kojeg je delovala i filološka sekcija.

U ono vreme, pisani katalonski jezik nije bio standardizovan; u štampanim tekstovima vladala je anarhija po pitanju gramatike i pravopisa. Zahvaljujući podršci Prat de la Ribe i Instituta, rad na normativizaciji, koji je započeo filolog Pompeu Fabra između 1913. i 1930. godine, dobio je institucionalni okvir. Rezultat je bio moderan, jedistven i normatizovan katalonski standardni jezik, sa normativnom gramatikom, rečnikom i pravopisom.

Referentni kod koji je predložio Pompeu Fabra - ono što danas nazivamo standardnim jezikom - u upotrebi je do dana današnjeg. Ovaj kod je nad-dijalekatski, jer ne počiva samo na varijetetu Barselone, već uključuje mnoge elemente varijeteta koji se govore na Balearima i u Valensiji. Fabrin predlog standardnog varijeteta predstavljao je kompromis između različitih govornih zajednica katalonskog jezika, na čemu i počiva uspeh njegove jezičke reforme i kodifikacije.

Uprkos određenom otporu i polemici koju je Fabrina norma najpre izazvala, ona je ipak veoma brzo prihvaćena u najširim krugovima katalonskog društva, pre svega u štampi, izdavačkim kućama, kao i među katalonskim piscima.

Ustav Druge španske Republike iz 1931. godine, kao i Statut autonomije Katalonije iz 1932. godine vratile su Kataloniji autonomiju u upravi i Vladu (Generalitat), a katalonski je, uz kastiljanski, proglašen za zvaničan jezik. To je značilo i snažnu podršku podučavanju katalonskog jezika u školama, na svim nivoima obrazovanja.

S druge strane, zbog početka građanskog rata 1936. godine, na Balearima i u Valensiji nije došlo do proglašenja autonomnog statusa.

\section{Diktatura i progon katalonskog jezika}

Između 1939. i 1975. godine, tokom diktature Fransiska Franka (Francisco Franco) koja je usledila nakon španskog građanskog rata (1936-1939), katalonski je, kao i drugi manjinski jezici u Španiji, poput galisijskog i baskijskog, bio sistematski progonjen, naročito 40-tih i 50-tih godina. Frankov režim zabranio 
je upotrebu ovog jezika u obrazovanju, zabranio je štampanje knjiga, časopisa i novina, slanje telegrama, pa čak i obavljanje telefonskih razgovora na katalonskom. Saobraćajni znaci, oznake svih institucija i prodavnica, kao i celokupna slika Španije prema spoljnom svetu - sve je bilo na kastiljanskom. ${ }^{9}$

Tokom 50-tih i 60-tih godina, kada je industrijalizovanu Kataloniju zahvatio snažan talas migracija iz ostalih delova Španije, nigde na katalonskim teritorijama nisu postojali obrazovni niti demokratski resursi koji bi novopridošlom stanovništvu omogućili učenje katalonskog jezika (Vallverdú, 1984). Novopridošli migranti poticali su mahom iz ruralnih delova Španije a nastanjivali su se najviše na području Barselone, ali i na Balearima i Valensiji.

Ovi migrantski talasi kastiljanskih govornika radikalno su promenili sociolingvističku realnost Katalonije i ostalih katalonskih teritorija. Katalonski je prestao da bude dominantan jezik na ulici, naročito u provinciji Barseloni, gde je 1975. godine živelo 70\% stanovništva Katalonije.

Uprkos svemu, katalonski jezik je ostao jezik porodične transmisije u porodicama katalonskog porekla, kako u Kataloniji tako i na Balearima a u nešto manjoj meri i u Valensiji.

Međutim, uprkos zabranama, mnogi su pisci, obrazovani i sazreli u prethodnoj eposi, nastavili da tokom frankističke diktature pišu na katalonskom, mada mahom u egzilu. Neki od najvažnijih među njima (a prevedeni na srpski) jesu Merse Rodoreda (Mercè Rodoreda), Đuzep Pla (Josep Pla), Pere Kalders (Pere Calders), Visent Andres Esteljes (Vicent Andrés Estellés) i Ljorens Viljalonga (Llorenc Villalonga).

\section{Jezičke politike u demokratiji}

Posle Frankove smrti (1975), u Španiji su obnovljene demokratske institucije sistema. Ustavom iz 1978. godine Španija je priznata kao multijezička država i utvrđeno da, osim kastiljanskog, i drugi jezici Španije mogu biti zvanični, u skladu sa statutima autonomnih pokrajna.

Tako statuti Katalonije (1979) i Balearskih ostrva (1983) priznaju katalonski kao autohtoni jezik ovih pokrajna, dok je status pokrajne Valensije (1982) za zvaničan jezik, uz kastiljanski, proglasio valensijanski (valencià), što je naziv za varijetet katalonskog jezika koji se govori na teritoriji autonomne pokrajne Valensije. Nešto kasnije, i Ustav kneževine Andore (1993) proglasio je katalonski za zvaničan jezik ove države.

Pod okriljem autonomnih statuta, skupštine Katalonije, Balearskih ostrva i Valensije donele su zakone o zaštiti katalonskog jezika, koji je uveden u škole, državnu administraciju i medije.

${ }^{9}$ Francesc Valverdú, “A sociolinguistic history of Catalan”, International Journal of the Sociology of Language, 47, 1984, str. 13-29. 
U Kataloniji je 1983. zakonom o jezičkoj normalizaciji pokrenut proces obnavljanja poznavanja i upotrebe katalonskog jezika na tri glavna plana, institucionalnom, medijskom i obrazovnom, na osnovu čega su razvijeni akcioni planovi za obnovu svih domena upotrebe jezika. Na institucionalnom planu, katalonski je postao jezik katalonske Vlade (Generalitat), Skupštine (Parlament) i svih nivoa lokalnih vlasti. Vlada je osnovala i organe poput TERMCAT, koji se od 1985. brine o terminologiji na katalonskom, ili Konzorcijum za jezičku normalizaciju, koji radi na širenju domena upotrebe katalonskog jezika.

Što se obrazovnog sistema tiče, 1982. godine u Kataloniji je uveden model po kojem je katalonski, pored kastiljanskog, uveden kao jezik nastave. Ovaj model smatran je veoma uspešnim, budući da su deca i mladi, prošavši kroz obrazovni sistem, sticali kompetencije na oba jezika. ${ }^{10}$ Ipak, treba naglasiti da mnogi bilingvalni govornici, uprkos tome što su ga naučili u školi, ne koriste katalonski u svakodnevnoj komunikaciji. Ovo je naročito uočljivo u urbanim sredinama.

Što se tiče upotrebe katalonskog u medijskoj sferi, od 1976. godine nastali su brojni mediji, među kojima se po uticaju i dometu posebno ističu Televisió de Catalunya, Catalunya Ràdio i RAC1. Danas postoji više od 20 televizijskih kanala i preko 100 radio emisija na katalonskom (kako u javnom, tako i u privatnom vlasništvu). Katalonski je povratio status u štampanim medijima, tako da danas više od 30 dnevnih novina (štampanih i digitalnih) i oko 150 časopisa izlazi na ovom jeziku.

\section{Novi izazovi XXI veka}

U periodu između 90-tih godina prošlog i prve decenije ovog veka, teritorije katalonskog jezika primile su nov talas useljenika, ovaj put poreklom mahom iz zemalja van EU: Latinske Amerike, zemalja Magreba i iz Istočne Evrope (naročito Rumunije). Samo se u Kataloniju doselilo preko milion migranata, od kojih je većina smatrala španski a ne katalonski jezikom potrebnim za život u novom okruženju. Tako je katalonski počeo da se povlači pred kastiljanskim u mnogim sferama ekonomskog i društvenog života Katalonije. U poslovnom svetu, na primer, poznavanje katalonskog je dodatno vrednovano (u zavisnosti od konkretne pozicije i zahteva posla, na primer, u državnoj administraciji), ali, za razliku od poznavanja španskog, nije neophodno. Zato većina imigranata bira španski, a ne katalonski, kao jezik svakodnevne komunikacije, dok kod kuće obično nastavlja da koristi svoje maternje jezike. Po nekim procenama, danas oko 600000 stanovnika Katalonije u privatnoj sferi koristi jezik koji nije ni katalonski ni kastiljanski. Jedno istraživanje Univerziteta u Barseloni identifikovalo je preko 300 različitih jezika koji se danas govore u katalonskim domaćinstvima.

${ }^{10}$ Miquel Strubell, "Language planning and bilingual education in Catalonia", Journal of Multilingual and Multicultural Development, 17(2-4), 1996, str. 262-275. 
Drugi činilac koji može objasniti ograničenu upotrebu katalonskog među imigrantima, bilo španskog ili nekog drugog porekla, jeste činjenica da mnogi govornici katalonskog u kontaktu sa osobama ne-katalonskog porekla automatski i nesvesno prelaze na upotrebu kastiljanskog. Katalonsko-kastiljanski bilingvizam predmet je istraživanja brojnih sociolingvističkih studija. U pitanju je asimetrični bilingvizam, budući da su uglavnom govornici katalonskog bilingvalni, dok su govornici kastiljanskog i imigranti uglavnom monolingvalni, na kastiljanskom. ${ }^{11}$ Najzanimljiviji zaključci novijih sociolingvističkih studija jesu da mnogi imiganti i pripadnici nižih društvenih slojeva smatraju katalonski jezikom srednje a kastiljanski jezikom radničke klase. ${ }^{12} \mathrm{U}$ mnogim školama u gradskim sredinama katalonski uživa status elegantnog i prestižnog jezika, dok se kastiljanski vrednuje kao prost, običan jezik. ${ }^{13}$

Iako je tačno da je katalonski danas identifikovan kao jezik srednje a španski kao jezik radničke klase u urbanim zonama Katalonije, istina je da su mnogi govornici katalonskog pripadnici radničke klase a da je kastiljanski tradicionalno bio jezik katalonske više klase. Naime, još od XV veka, dolaskom kastiljanske dinastije Trastamara na vlast u Aragonskoj kruni, katalonska aristokratija je pokazala snažan afinitet prema upotrebi kastiljanskog, umesto katalonskog jezika. U skorije vreme, za vreme frankizma, jedan deo katalonske buržoazije napustio je katalonski u korist kastiljanskog u svim domenima javne i privatne upotrebe. Danas je kastiljanski dominantan jezik trgovine i biznisa.

Pitanje bilingvizma ne izaziva samo akademsko interesovanje, već je postalo i deo javne debate u Kataloniji. O ovoj temi se često diskutuje u TV i radio emisijama, kao i u porodičnim i privatnim okvirima. Rašireno je uverenje da je svaki govornik katalonskog sociolingvista-amater, sa jasno oformljenim stavovima o vrednosti i budućnosti katalonskog jezika.

Jedna od najčešće vođenih diskusija poslednjih decenija jeste ona o vitalnosti katalonskog jezika, tj. da li je katalonski u opasnosti zbog prisustva tako dominantnog jezika, kao što je španski, na njegovoj teritoriji. Poslednjih godina, zbog snaženja katalonskog pokreta za nezavisnost, javljaju se i debate o tome kakav zvaničan status treba da imaju katalonski i kastiljanski u slučaju proglašenja nezavisne katalonske Republike.

${ }^{11}$ Mnogi imigranti poreklom iz hispanoameričkih zemalja su monolingvalni, mada određeni broj njih govori i neki od autohtonih amerindijanskih jezika. Međutim, imigranti poreklom iz drugih delova sveta (iz arapskih zemalja, subsaharske Afrike, Rumunije, Ukrajine i dr.) nisu monolingvalni, budući da pored španskog govore i svoje maternje jezike.

${ }^{12}$ Víctor Corona, "Latino trajectories in Barcelona: A longitudinal ethnographic study of Latin American adolescents in Catalonia", Language, Culture and Curriculum, 29(1), 2016, str. 93-106.

${ }^{13}$ Kathryn Woolard, "Linguistic Consciousness among Adolescents in Catalonia: A Case Study from the Barcelona Urban Area in Longitudinal Perspective", Zeitschrift für Katalanistik, 22, 2009, str. $161-172$. 
Ukratko, četiri decenije posle Frankove smrti, sociolingvistička situacija katalonskog jezika nije ohrabrujuća; nema sumnje da je katalonski od 80-tih do danas izgubio trku protiv kastiljanskog na društvenom terenu, naročito $u$ urbanim zonama. Katalonski je, takođe, na svim svojim teritorijama neprestano izložen opstrukcijama od španske države, kao što pokazuju ova dva primera: to što katalonski još uvek nije proglašen za zvaničan jezik EU i to što je svega $8,4 \%$ sudskih presuda u Kataloniji 2015. godine bilo izrečeno na katalonskom jeziku.

Međutim, postoje i razlozi za optimizam. Naime, od 80-tih je učinjen ogroman napredak u promovisanju katalonskog kao jezika institucija, kako obrazovnih tako i administrativnih. Katalonski je i jezik dinamične književne produkcije, pozorišta, filma kao i masovnih medija i novih tehnologija. Drugim rečima, uprkos izazovima koje predstavlja prisustvo globalno dominantnog jezika, poput španskog, na teritoriji katalonskog jezika, savremene jezičke i kulturne politike u Kataloniji uspevaju da uspešno odbrane status katalonskog u brojnim - mada ne svim - domenima jezičke upotrebe.

\section{LITERATURA}

Banniard, Michel, "The Transition from Latin to Romance Languages" in The Cambridge History of Romance Languages, ed. M. Maiden et al., Cambridge, Cambridge University Press, 2013, pp. 57-106.

Boix-Fuster, Emili \& Farràs, Jaume, "Is Catalan a medium-sized language community too" in Survival and development of language communities prospects and challenges, ed. F. X. Vila, Bristol, Multilingual Matters, 2012, pp. 157-178.

Corona, Víctor, "Latino trajectories in Barcelona: A longitudinal ethnographic study of Latin American adolescents in Catalonia", Language, Culture and Curriculum, 29(1), 2016, pp. 93-106.

Ferrando, Antoni, \& Nicolás, Miquel, Història de la llengua catalana. Barcelona, Editorial UOC, 2011.

Gimeno Blay, Francisco, "Modelos de transmisión textual de los sermones de San Vicente Ferrer: la tradición manuscrita", Anuario de Estudios Medievales, 49(1), 2019, pp.137-169.

Strubell, Miquel, "Language planning and bilingual education in Catalonia”, Journal of Multilingual and Multicultural Development, 17(2-4), 1996, pp. 262-275.

Valverdú, Francesc, "A sociolinguistic history of Catalan”, International Journal of the Sociology of Language, 47, 1984, pp. 13-29.

Woolard, Kathryn, "Linguistic Consciousness among Adolescents in Catalonia: A Case Study from the Barcelona Urban Area in Longitudinal Perspective", Zeitschrift für Katalanistik, 22, 2009, pp. 161-172 
Wright, Roger, "Periodization" in The Cambridge History of Romance Languages, ed. M. Maiden et al., Cambridge, Cambridge University Press, 2013, pp.107-124.

Pau Bori

Ana Kuzmanović Jovanović

\section{LA LENGUA CATALANA: EL CONTEXTO HISTÓRICO, POLÍTICO Y SOCIAL \\ (Resumen)}

El propósito del presente artículo es presentar el desarrollo del contexto histórico, político y social de la lengua catalana, así como la situación sociolingüística actual en los territorios de habla catalana. Dicho desarrollo se expone de una manera cronológica, empezando por los orígenes del catalán a finales de la Alta Edad Media, siguiendo por su expansión territorial y el considerado como el siglo de oro de su literatura (s. XV). A continuación, explicamos la pérdida de poder político y cultural agravada en el siglo XVIII, la revitalización de la lengua en la segunda mitad del siglo XIX y su normativización en primeras décadas del siglo XX, así como su persecución durante la dictadura franquista. Por último, presentamos la situación sociolingüística contemporánea en los territorios donde se habla catalán, en el marco de las nuevas tendencias demográficas, políticas y socioeconómicas.

Palabras clave: catalán, historia sociolingüística, Cataluña, bilingüismo.

Примљено 11. новембра 2019, прихваћено за објављивање 10. децембра 2020. године. 